\title{
The interstitial mechanisms of regulation of cell growth and the role of the immune system: a new immune theory of aging
}

\begin{abstract}
A theoretic modeling of the specific features of self-regulation of an organism's cell growth has shown that specialized cell populations should exist to carry out intercellular regulation of the growth of various types somatic tissues. Based on the data of immunology and cell biology, it is suggested that such a system should be represented by specialized T-lymphoid cells. The age-related decrease in the function of such regulatory cells may be the main mechanism of aging of the organism's selfrenewing somatic tissues and may determine an age-related decrease in the growth potential of tissues of an aged organism.
\end{abstract}

Keywords: aging, theory of aging, immunity
Volume 2 Issue 4 - 2017

\author{
Dontsov VI \\ Federal Research Center, Russia
}

Correspondence: Dontsov VI, Institute for Systems Analysis, Federal Research Center, "Computer Science and Control” of Russian Academy of Sciences, 1 I73 I 2 Russian, Moscow, 60-let Oktjabrja str.9, Russia,Email dontsovvi@mail.ru

Received: May 15, 2017 | Published: June 13, 2017

\section{Introduction}

The self-organization and self-renewal of tissues require a specialized cell system to regulate cell growth.

The problem of regulating cell division and cell growth is undoubtedly one of the most fundamental problems of both theory and practice of contemporary biology and medicine. Modern theories of aging suggest a close relationship of aging and the processes of growth and development, also consider the age-related decrease in cellular self-renewal of tissues due to their decreased growth potential to play the most important role during the development of the aging process. $^{1-9}$

Highly organized multicellular organisms contain a huge number of dividing cells of various tissues and organs which grow and renew themselves at different rates. Thus, the very existence of multicellular organisms is associated with reliable systems of coordination and mutual concordance between the processes of cell division and tissue growth; however, at present our knowledge of them is insufficient. The regulation processes in complicated developing systems are now being considered using an adequate theoretical apparatus-theories of self-organization which are elaborated, for instance, in the context of synergetics and cybernetics. ${ }^{4,10-17}$

"Hypercycle" is one of the most important concepts in this field; it is defined as "a concept of intrinsic self-organization that determines the integration and coordinated evolution of a system of functionally related self-replicating units". ${ }^{18}$

The hypercycle theory is based on the evident inevitability of the generation during evolution of higher order regulatory relations between self-replicating units and systems of lower order (e.g., between cells or cell populations), which form a new unified super system of a higher level. Such interrelations in many cases can be modeled using simple and descriptive schemes, formulas, and diagrams. This modeling is of help in finding out the significant moments of the general and particular essence when specific physiological processes are studied. Let us consider some general concepts of this kind. Cell growth can be formally presented as the movement of cells from the rest phase $(\mathrm{G})$ into the proliferation phase $(\mathrm{S})$, and then, as a result of cell growth and cell division, the two new $\mathrm{G}$ cells appeared: $\mathrm{G}-\mathrm{S}-2 \mathrm{G}$.

Most generally, cell division can be modeled as an increase in the number of a certain type of cell (e.g., G) and without other influences, this results only in an infinite increase in the number of cells according to the following law: $\mathrm{dG} / \mathrm{dt}=\mathrm{k} \mathrm{G}$ (i.e., change in the number of cells is proportional to their number at am moment in time).

Since under real conditions an infinite increase in cell growth would very rapidly cause death in a real multicellular organism, a process must exist the limit of the number of cells and is dependent on it, which is known as negative feedback: $\mathrm{dG} / \mathrm{dt}=\mathrm{k} 1 \mathrm{G} /(\mathrm{k} 2 \mathrm{G}+$ const $)$.

It is these speculations that gave rise to the concept of the chalone system of self-regulation, which works for one cell population. Cell population growth is limited, and the growing cells inhibit the entrance of the rest of the cells into the growth phase:

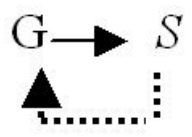

Further considerations can be reduced to similar processes of selforganization, but for several different cell populations. In this case, each cell population, which has its own chalone system, is considered to be a separate elementary system, and a self-organization process will take place between them according to the same laws (formulas); however, now "G" should designate a definite cell population of the organism (e.g., hepatocytes or skin cells, etc.- Ga).

In the formula for the growth of cell numbers, $\mathrm{dG}$ is now proportional to the number of cells in the population having a stimulating effect and is inversely proportional to the number of cells with an inhibiting effect. The particular appearance of the formulas can differ somewhat, but all of them have been shown by numerical analysis to give virtually the same results, which are presented in a general form. The minimum number of cell populations, which form a "cellular hypercycle" (we shall call this super system by this name) is 
equal to three: two populations stimulate each other (Ga and $\mathrm{Gh}$ ) and one of them inhibits the growth of the others $(\mathrm{Gi})$ :

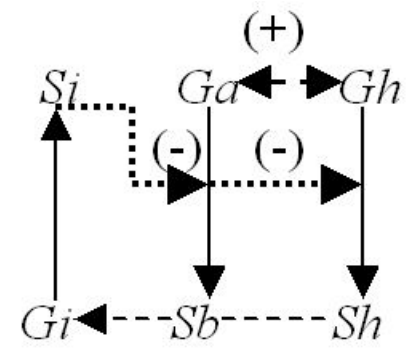

This cellular hypercycle is described by its features as follows: self-renewal, self-regulation, self-recovery (which is the same for the present consideration).

Subsequent trends in the evolution of this hypercycle are clear: first, an increase in the number cell populations; second, specialization:

A. Indirection of special functions (the formation of the e.g., liver, kidneys, and skin: $\mathrm{Ga}, \mathrm{Gb} . . . \mathrm{Gn})$ :

B. In direction of cell growth regulation by isolation of stimulating (Gh) and inhibiting (Gi) populations of regulatory cells into a special system (let us call it a "system of cellular regulation of proliferation (SRP)".

In terms of immunology and theories of "regulatory nets," this can be presented as a positive selectiol specific clones, e.g., lymphocytes, during idiotoip-organ interactions. In its final form, the SRP should also take into account the appearance the evolution of the deep rest phase (Go) for the cells functional organs and tissues, because tissue function is of great importance for the organism as a whole; however, the appearance of such a phase only complicate the function of regulatory cells of the CRP-system. It should be emphasized that such a system as a whole is stable and possesses properties of selfformation, self-recovery, and conversion into the stable state under any disturbance - external influence.

\section{T-lymphocytes as regulators of somatic cell growth}

The main issue from the above is: what cells are crucial for the regulation of somatic cell growth in contemporary humans and mammals? Both theoretical concepts and experimental data clearly indicate that the main role in these processes belongs to T-lymphocytes-regulators (helpers and suppressors), namely, to their nearest precursors (presumably, nonspecific CRP) and to T-cells, which participate in the "syngenic mixed lymphocyte culture" (sMLC), and react to own cells of organism, unlike immune cells, which react to "alien (for the specific CRP).

In fact, based on the requirements, which are theoretical consequences of the above-mentioned scheme, it is evident that the suggested specific features of CRP coincide with the properties of regulatory lymphocyte populations (mainly T-lymphocytes). It must be:
A. Movable (recirculating) in the organs;
B. Must have receptors "to one's own" and recognize their "own";
C. Possess its own proliferation;
D. CRP cells should be involved in regulation of the proliferation

of any type in cells of the organism, including lymphocytes-effectors in the immune response, etc.

On the other hand, there are data indicating that it is exactly lymphocytes that play a major part in the regulation of cell growth, not only of immune cells but of any type of cells in the organism. These works are so important that they were awarded an author's certificate of discovery in the USSR, and die most important work in this field has been done by Russian scientists. The importance of lymphocytes for regeneration processes has long been known, even before the formation of modern immunology, ${ }^{19,20}$ as a stimulating effect of immunotropic funds on regeneration processes. ${ }^{21}$

The greatest attention both here and abroad was paid to studies concerned with the lymphocyte transfer of "regeneration information": lymphocytes taken from animals with regenerating tissue of any type and transferred to intact syngenic animals were found to induce mytoses and cell growth of the appropriate type of tissue..$^{22-25}$ The transfer of the hyperplastic reaction by lymphocytes is possible for any tissue and any process, e.g., isoproterenol-induced hypertrophy of the salivary gland of rodents, functional heart hyperplasia etc. ${ }^{3,23,26,27}$

The regulation of fibroblast proliferation by T-lymphocytes, including the release of fibroblast-specific lymphokines, is well known. It was shown also that signs of bone tissue growth - osteopetrosis, are corrected by transfer of lymphocytes from healthy animals; moreover, parathyroid hormone, which is specific for osteoclasts, produces the effect through T-lymphocytes, which have receptors to this hormone unlike the osteoclasts. ${ }^{28,29}$ General growth inhibition, e.g., dwarfism in mice, can be prevented by the transfer of lymphocytes from healthy animals; and T-lymphocytes have receptors to the growth hormone and their number increases in the period of the animals' growth. ${ }^{30}$

There is a known paradox of "nude" mice, which contradicts the theory of tumor supervision (tumor supervision was thought to be the main evolutionary factor in lymphoid system development): the incidence of spontaneous and induced tumors in thymus-free mice is decreased rather than increased. Moreover, the transfer of lymphocytes from normal mice restored the usual incidence of tumors in them. The decreased regeneration and tissue renewal (the dystrophy syndrome) in these animals cannot be explained only by decreased immunity and bacterial infection. T-lymphocytes appear in these mice with time. Thus, the role of the thymus is played by ordinary tissues, which also stimulate the proliferation and maturation of T-cells. ${ }^{31,32}$

Facts are known of cases where lymphocytes stimulate and inhibit tumor growth, and these effects are not reduced to the typical "killer" or other purely immune phenomena. ${ }^{33-35} \mathrm{~A}$ decrease in cell renewal (physiological regeneration) during aging is preceded by degeneration of the thymus, which is a source of T-lymphocytes; were proposed the immune theory of aging; symptoms of ageing can be transferred to syngeneic transfer of lymphocytes from old mice. ${ }^{36-39}$

The "graft-versus-host" reaction leading to the inactivation of the host's own lymphocytes are accompanied by typical "nonimmune" symptoms a decrease in the induced regeneration, tissue degeneration, etc. The system of T-cell-regulators is much more complex than the systems of T-and B-effectors of immunity, and moreover, T-cells of the immune system recognize a foreign antigen ("not its own") in a complex with "its own"-with antigens of the major histocompatibility complex.

The science of immunology presents thorough studies and detailed 
descriptions of the so-called "syngenic mixed lymphocyte culture" (sMLC), when T-cells, mainly of the T-helper and T-suppressor type, show a vigorous proliferation in response to the organism's own cells, including nonimmune ones. These are "surplus" cells in classical immunology and they can be removed by antisera without changes in the ordinary immune reactions. ${ }^{2,40-42}$ However, the context of sMLC, attention should be paid the data on the appearance or increase in the number of receptors on the nonimmune cells of various tissue including tumors during their preparation for cell division, because these receptors provoke the react of T-cells.

Therefore, we have suggested that the function o regulation of cell growth of "one's own" cells is phylogenetically more ancient and more important, then immunity itself. T- and B-effectors of immunity are phylogenetically younger. In this case, the immune system is part of more general and complex system of cell growth regulation - the SRP.

Proceeding from the data discussed above, cell general conclusions can be made.

1. A special system regulating somatic tissue growth must exist on the intercellular level, which originated, developed, and became complicated very early during evolution.

2. The CRP which include certain populations of T-lymphocytes (for contemporary mammals) are units of this system.

3. Other types of cells can also form units of this system, and this permits us from following its development during evolution (first and foremost, these are macrophages and large granular lymphocytes).

4. This system mediates many regulatory influences of hierarchically higher systems (e.g., hormonal influences).

5. The functions of this system are distinctly described and modeled.

6. During evolution, it necessary to regulate cell growth in the multicellular organism and not supervise tumors that caused a generation of the complicated T-lymphoid system, which is considered in immunology to be a regulatory system only for immunocytes.

7. CRPs can be isolated and studied, their activity can be influenced, and they can be used to obtain specific and nonspecific regulatory factors, which affect various physiological and pathological processes.

8. The SRP is a special system separate from the immune system of the organism and responsible for more general and important tasks than the immune system. The immune system can be considered to be a specialized part of the SRP-system.

\section{A new immune-regulatory theory of aging}

With regard to significance of the decreased cell growth potential of somatic tissues in the aging process of the multicellular organisms, a new immune theory of aging has been developed, which emphasizes the important role of age-related deficiency of the lymphocytedependent regulation of somatic tissue growth during aging. Agerelated deficiency of lymphocyte-dependent regulation of somatic tissue growth is a crucial mechanism of aging in multicellular organisms. ${ }^{3,10}$
After the appearance of the immune theory of formulated aging by F. Bernett, functions of the immune system during aging were comprehensively studied and their definite relation to the aging process was shown:age-related progressive atrophy of the thymus and lymphoid tissue as a whole, a decrease in expected lifetime with a decrease in the number of circulating T-lymphocytes, the similarity of senile changes and the consequences of early thymectomy and other immunodeficiencies, immune disorders, and damaged expression of histocompatibility antigens in progeria, etc.

Age-related changes are found in all functions of the immune system, especially those of the immune T-system:

A. Atrophy of the thymus, spleen and lymph nodes;

B. A decreased number of peripheral T-cells and increased number of immature lymphocytes due to delay in their differentiation;

C. A decreased number of T-cell precursors;

D. A pronounced decrease in the production of thymus hormones associated with the activation of T-suppressor mechanis$\mathrm{ms}$ and nonspecific T-helpers and T-suppressors to lead to the release of autoimmune processes;

E. A decreased variety of lymphocyte antigen decreased production of interleukin-2 by T-helpers pronounced decrease in lymphocyte activation by organism's own cells; i.e., a decrease in syngeneic lymphocyte culture;

F. Decreased anti-tumor resistance of the organism, etc.

However, attempts to theoretical link two processes: age-related increased lymphoid dystrophy all decreased self-renewal of other tissues, which is the main mechanism of aging in self-renewing tissues have failed.

This age-related decrease in self-renewal of vary tissues is known to be accompanied by the development of a generalized G1/S block of proliferation: the cells prepared for proliferation is increased, but they are not stimulated for proliferation. However, the reason for this block is well known in immunology for lymphocyte-effectors of senile animals; produced by an imbalance in the functions of T-lymphocyteregulators. This is manifested by a reduction of the total number of T-regulators and an increased fraction of T-inhibitors. These data, along with the known sharply decreased SMLC in senility, correlate with above-mentioned concepts of the CRP-system in organism. We have proposed a new lymphoid theory aging. Its main statements are as follows:

A. A decrease in the self-renewal of cells is a leading mechanism somatic tissue aging.

B. The decrease of cell growth of somatic tissues during aging is determinated by changes in the system of lymphoid regulation of somatic cell proliferation.

C. The essence of this changes in the SRP in senility is an increase in the fraction of CRP inhibitors and an absolute decrease in total number of CRP.

D. The disrupted ratio between the stimulating and inhibiting types of CRP results in a decreased rate of somatic cell passage from G1 phase and generation of the G1/S block in tissues of aged animals. 
E. The declining proliferative activity somatic tissue cells increases the "aged" cell fraction and "senile" changes are caused by the manifestation normal properties of such cells with a prolonged life time, which are in a permanent state of differentiation.

F. Since there are continuous processes of cell renovation going on in tissues, processes of adaptation, hypertrophy etc. take place along with aging processes.

G. Change in the SRP result from the continued influence of regulators, which limit the growth of the organism after growth termination, with the involvement of the hypothalamic pituitary system and thymus.

Thus, the function of T-lymphocytes is suggested decrease sharply during aging due to changes in the organism's regulatory systems. We have discovered a variety of experimental evidence and have shown that it is possible to reactivate and rapidly (in days and hours) regenerate the growth potential of somatic cells under the influence of the CRP. ${ }^{2,3,10,33,43,44}$ Thus, the proposed new immune theory is not only of theoretical interest but also makes it possible to use the whole potential of immunopharmacology to counteract one of the crucial mechanisms of aging: the age-related decrease in cell self-renewal in the multicellular organisms, including mammals and humans.

\section{Conclusion}

The existence of multicellular organisms requires the presence of reliable regulatory systems to coordinate and interrelate processes of cell division and tissue growth. The most important level of regulation is represented by the system of intercellular regulation of cell growth of various types of somatic tissues. The theoretical modeling of specific features of self-formation and self-regulation of such a system shows that specialized cell populations should exist to provide the intercellular regulation of somatic tissue growth. Based on the experimental data of immunology and cell biology, we suggest that the system includes specialized T-cells of stimulating and inhibiting populations which in the "syngeneic mixed lymphocyte culture" react to the organism's own growing cells. The age-related decrease in the function of such T-regulating cells may be a crucial mechanism of aging of the organism's self-renewing somatic tissues and may determine the age-related decrease in the growth potential of tissues of the senile organism.

\section{Acknowledgements}

None.

\section{Conflict of interest}

The author declares no conflict of interest.

\section{References}

1. Atwood CS, Bowen RL. The reproductive-cell cycle theory of aging: an update. Exp Gerontol. 2011;46(2-3):100-107.

2. Dontsov VI. Theoretical prerequisites for an experimental corroboration of the existence of a specialized cellular system in control of multicellular organism tissue proliferation. J hyg epidemiol microbial immunol. 1987;31(2):209-217.

3. Dontsov VI. Lymphocyte regulation of cellular growth of somatic tissues and a new immune theory of aging. Fiziol Cheloveka. 1998;24(1):82-87.
4. Dontsov VI, Krutko VN. Biological age as a method for systematic assessment of ontogenetic changes in the state of an organism. Ontogenez. 2015;46(5):295-303.

5. Khokhlov AN. Impairment of regeneration in aging: appropriateness or stochastics? Biogerontology. 2013;14(6):703-708.

6. Kirkwood TB, Melov S. On the programmed/non-programmed nature of ageing within the life history. Curr Biol. 2011;21(18):701-707.

7. Rando TA, Chang HY. Aging, rejuvenation, and epigenetic reprogramming: resetting the aging clock. Cell. 2012;148(1-2):46-57.

8. Vanhaelen Q. Aging as an optimization between cellular maintenance requirements and evolutionary constraints. Curr Aging Sci. 2015;8(1):110119.

9. Walker RF. Developmental theory of aging revisited: focus on causal and mechanistic links between development and senescence. Rejuvenation Res. 2011;14(4):429-436.

10. Dontsov VI. Structural models of regulation of cell growth and a new immune theory of aging. Sistemnyj analiz i upravlenie v biomedicinskih sistemah. 2011;4:125-127.

11. Dontsov VI, Krutko VN. System mechanisms and generalized models of aging. Informatika $i$ sistemy upravlenija. 2009;4:30-31.

12. Dontsov VI, Krutko VN. General system theory of aging. Sistemnyjy analis $i$ upravlenie $v$ biomeditsinskih sistemah. 2012;11(3):657-663.

13. Krutko VN, Dontsov VI, Zakhariashcheva OV. The system theory of aging: methodological principles, basic tenets and applications. Aviakosm Ekolog Med. 2009;43(1):2-19.

14. Lazko EA, Lazko MV, Yaroshinskaya AP, et al. Use of structurally-system analysis in biology. Astrahanskij medicinskij zhurnal. 2012;7(4):163-165.

15. Nicolis JS. Dynamics of hiperarchical systems. An evolutionary approach. Springer-Verlag. NY Tokyo, Japan: Berlin-Heidelberg; 1986. $397 \mathrm{p}$.

16. Sergeev SA, Kobzar KP. Systemic-anti-systemic analysis- a way to voluminous thinking. Sovremennye nauchnye issledovanija i innovacii. 2014;3(35):16.

17. Wolfram S. A new kind of science. Champaign, Ill, USA. Wolfram Media Inc; 2002.

18. Eigen M, Schuster P. The hypercycle. A principle of natural self-organization. Part A: Emergence of the hypercycle. Naturwissenschaften. 1977;64(11):541-565.

19. Burwell RG. The role of lymphoid tissue in morphostasis. Lancet. 1963;2(7298):69-74.

20. Davies AJ, Leuchars E, Doak SM, et al. Regeneration in relation to the lymphoid system. Nature.1964;201:1097-1101.

21. Giełdanowski J. Immunomodulatory drugs as the stimulators of proliferative process. Arch immunol ther exp (Warsz). 1983;31(3):345-348.

22. Babaeva AG. Past, present and future problems of regulation of lymphoid non-lymphoid cells. Bjulleten' jeksperimental'noj biologii $i$ mediciny. 1995;9:230-234.

23. Nesterenko VG. A concept of immune regulation of somatic cell differentiation. $J$ theor boil. 1984;107(3):443-456.

24. Timoshevich TV, Kharlova GV, Yudina N. Regenerative transmission of information by lymphocytes of rats with extensive bowel resection. Bjulleten'jeksperimental'noj biologii i mediciny. 1984;3:352-355. 
25. Shilova LJ, Poltorakin VS, Suslova AP. Effect of donor splenic lymphocytes treated with carbon tetrachloride on liver mitotic activity and alpha-fetoprotein production in syngeneic recipients. Biull Eksp Biol Med. 1982;93(6):99-101.

26. Dontsov VI. Isoproterenol-induced lymphocyte-dependent hyperplasia salivary glands in mice-a possible analogue of syngeneic mixed lymphocyte culture in vivo. Bulletin of Experimental Biology and Medicine. 1987;104(5):1612-1614.

27. Svet Moldavsky GJ, Shkhvatsabaya IK, Zinser SN. A study of passive transfer of lymphoid cells compensatory myocardial hypertrophy. Doklady akademii nauk SSSR. 1974;218(4):246-249.

28. Schneider GB, Relbsom M. Immunological competence in osteopetrotic rets. Immunology. 1984;167:318-324.

29. Horowitz M, Vignery A, Gershon R, et al. Thymus-derived lymphocytes and their interactions with macrophages are required for the production of osteoclast-activated factor in the mouse. Proc Nat Acad Sci USA. 1984;81(7):2181-2185.

30. Payan DG, Hess KA, Geetzl EJ. Inhibition by somatostatine of the proliferation of T lymphocytes and Melt-4 lymphocytes. Cel Immunol. 1984;84(2):433-438.

31. Rygaard J, Povlsen CO. The absence of spontaneous tumors in nude mice. Proc 1st int works on nude mice stuttgart; 1974. p. 293-296.

32. Wortis HH. Immunological studies of the nude mice. Contemp Top Immunobiol. 1974;3:243-263.

33. Dontsov VI. The Influence of lymphocytes on the growth of transplantable adenocarcinoma of the colon in mice. Jeksperimental'naja onkologija. 1989;11(5):48-51.

34. Ponzio NM. Similarities between the syngeneic mixed lymphocyte response and lymphoma-induced $\mathrm{T}$ cell proliferation in $\mathrm{SJL} / \mathrm{J}$ mice. Behring Inst Mitt. 1983;72:28-30
35. Malygin AM, Pogodina ON, Chernysheva MD, et al. Study of antitumor action of lymphocytes of young mice and hepatectomies line C3HA. Immunologija. 1984;4:46-49.

36. Babaeva AG, Zuev VA. Deferment of the signs of aging in young mice by lymphocytes from old donors. Bjulleten'jeksperimental'noj biologii mediciny. 2007;144:89-90.

37. Burnet FM. An immunological approach to ageing. Lancet 1970;2(7668):358-360.

38. Harrison DE, Archer JR, Astie CM. The effect of hypophysectomy on thymus age in mice. J Immunol. 1982;129(6):2673-2677.

39. Walford RL. The Immunological theory of aging. Immunological Reviews. 1969;2(1):171.

40. Bryson JS, Jones LA, Caywood BE, et al. In vivo regulation of the murine syngeneic mixed lymphocyte reaction. Cell Immunol. 1990;129(1):138150 .

41. Gutowski JK, Weksler ME. Studies on the syngeneic mixed lymphocyte reaction I. The ontogeny of the syngeneic mixed lymphocyte reaction in mice. Immunology. 1982;46(4):727-736.

42. Kimura S, Fukai T, Morisaki I, et al. Senescence-related change in autologous mixed-lymphocyte reaction in senescence-accelerated mice. Mech Ageing Dev. 1997;99(1):19-32.

43. Dontsov VI. Application of the hypercycle theory on analyze processes of intercellular regulation of tissue proliferation. Uspehi sovremennoj biologii. 1979;87:3-15.

44. Chizhov YA, Senchuk YS, Krutko VN, et al. The Application of the corrector of immune system Transfer factor for the decrease of human biological age. Technologii zhivyh system. 2013;10:41-46. 